\title{
Anemia Control in Kidney Transplant Recipients Using Once-Monthly Continuous Erythropoietin Receptor Activator: A Prospective, Observational Study
}

\author{
Klemens Budde, ${ }^{1}$ Thomas Rath, ${ }^{2}$ and Volker Kliem ${ }^{3}$ \\ ${ }^{1}$ Department of Nephrology, Charité, Medical University, 10117 Berlin, Germany \\ ${ }^{2}$ Department of Nephrology and Transplantation Medicine, Westpfalz Hospital, 67655 Kaiserslautern, Germany \\ ${ }^{3}$ Nephrology Center of Lower Saxony and Transplant Center, Vogelsang 105, 34346 Hann. Münden, Germany \\ Correspondence should be addressed to Volker Kliem; v.kliem@awogsd.de
}

Received 17 January 2014; Revised 24 March 2014; Accepted 24 March 2014; Published 4 May 2014

Academic Editor: Bruce Kaplan

Copyright (C) 2014 Klemens Budde et al. This is an open access article distributed under the Creative Commons Attribution License, which permits unrestricted use, distribution, and reproduction in any medium, provided the original work is properly cited.

\begin{abstract}
In a multicenter, prospective, observational study of 279 kidney transplant recipients with anemia, the efficacy and safety of oncemonthly continuous erythropoietin receptor activator (C.E.R.A.) were assessed to a maximum of 15 months. The main efficacy variable was the proportion of patients achieving a hemoglobin level of 11-12 g/dL at each of visits between months 7 and 9 . At study entry, 224 patients $(80.3 \%)$ were receiving erythropoiesis stimulating agent (ESA) therapy including darbepoetin alfa (98), epoetin beta (61), and C.E.R.A. (45). The mean (SD) time between C.E.R.A. applications was 34.0 (11.9) days. Among 193 patients for whom efficacy data were available, mean (SD) hemoglobin was $11.1(0.99) \mathrm{g} / \mathrm{dL}$ at study entry, 11.5 (1.1) g/dL at month 7, 11.6 (1.3) g/dL at month 9, and 11.4 (1.1) g/dL at month 15. During months 7-9, 20.7\% of patients had all hemoglobin values within the range $11-12 \mathrm{~g} / \mathrm{dL}$ and $64.8 \%$ were within $10-13 \mathrm{~g} / \mathrm{dL}$. Seven patients (2.5\%) discontinued C.E.R.A. due to adverse events or serious adverse events. In this observational trial under real-life conditions, once-monthly C.E.R.A. therapy achieved stable hemoglobin levels in stable kidney transplant recipients with good tolerability, and with no requirement for any dose change in $43 \%$ of patients.
\end{abstract}

\section{Introduction}

Anemia is virtually universal at the time of kidney transplantation [1]. Chronic kidney disease (CKD) blunts erythropoietin production [2], a proanemic effect that is compounded by other factors such as accelerated erythrocyte destruction and widespread use of concomitant medication such as ACE inhibitors and ARBs [3]. Following transplantation, the prevalence of anemia declines sharply as renal function is restored but low hemoglobin $(\mathrm{Hb})$ levels persist in a worryingly large proportion of cases due to multiple factors such as suboptimal renal function, cardiovascular medication, and certain immunosuppressive therapies $[4,5]$. In the largest series to date, an analysis of 5,834 kidney transplant recipients at 10 European outpatient transplant clinics detected anemia in $42 \%$ of patients based on the American Society of Transplantation anemia guidelines $(\mathrm{Hb} \leq 13.0 \mathrm{~g} / \mathrm{dL}$ in males and $\leq 12.0 \mathrm{~g} / \mathrm{dL}$ in females) [6]. Using the same thresholds, large single-center cohort studies have found that $30-35 \%$ of kidney transplant patients have anemia [7-9]. In nontransplant CKD populations, anemia is predictive of cardiovascular events [10], mortality [11, 12], and diminished quality of life [13]. Posttransplant anemia is significantly associated with increased death-censored [14, 15] and all-cause $[9,16,17]$ graft loss, probably cardiovascular events [18] and possibly mortality [16-19], although causative relationships are not certain and anemia may be a marker for other pathologic processes.

Posttransplant anemia remains undertreated. In 2003, the Transplant European Survey on Anemia Management (TRESAM) analyzed a cohort of 4,263 patients from 72 centers in 17 countries and found that only $18 \%$ of patients with $\mathrm{Hb}<$ $11 \mathrm{~g} / \mathrm{dL}$ were receiving erythropoiesis stimulating agents (ESAs) [20]. In a follow-up study, five years later, this proportion had increased to just 24\% [6]. This low intervention rate may partly reflect missed diagnoses and safety 
concerns about ESA therapy to target high Hb levels [2124 ], but also the relative paucity of robust trials of ESA therapy in kidney transplantation. Findings from nontransplant populations cannot necessarily be extrapolated to kidney transplantation since the mechanisms underlying anemia and epoetin resistance may differ [3]. The available evidence in transplant patients, however, indicates that ESA therapy is effective in increasing $\mathrm{Hb}$ levels, based on data from two small randomized trials undertaken in the early posttransplant period $[25,26]$, a nonrandomized prospective multicenter study [27], an observational trial [28], and retrospective analyses $[29,30]$. Correction of posttransplant anemia with ESA is associated with improved quality of life [27]. However, questions remain. Results from the CHOIR [23] and CREATE [24] studies raised doubts about $\mathrm{Hb}$ targets in patients with CKD, leading to revised recommendations [31], an issue that is largely unexplored in kidney transplantation. Moreover, interventional studies typically report mean $\mathrm{Hb}$ values, and data relating to $\mathrm{Hb}$ fluctuation in individual kidney transplant patients are lacking.

Studies of ESA therapy in kidney transplantation have generally used epoetin or darbepoetin. Using these products, dosing is typically required thrice weekly for epoetin alfa or epoetin beta in the maintenance phase and at least every 2-4 weeks for darbepoetin. Continuous erythropoietin receptor activator (C.E.R.A.) is a modified recombinant human erythropoietin which has been designed to have a longer half-life than other ESA preparations [32]. As a result, correction of anemia can be achieved with dosing every two weeks in hemodialysis patients and once a month in nondialysis CKD patients, while during the maintenance phase, all patients require only once-monthly dosing [33], offering greater convenience for patients and healthcare staff.

The current multicenter, prospective, observational study was designed to evaluate the efficacy and safety of C.E.R.A. in anemic kidney transplant recipients, either administered de novo or following conversion from more frequently administered ESA therapies. The study design was developed with several points in mind. First, results from the CHOIR [23] and CREATE [24] studies raised doubts about $\mathrm{Hb}$ targets in patients with $\mathrm{CKD}$, leading to revised recommendations [33]. However, $\mathrm{Hb}$ levels in routine practice are largely undocumented in kidney transplantation. Second, recent Phase III trials of C.E.R.A. targeted an $\mathrm{Hb}$ level of not more than $13 \mathrm{~g} / \mathrm{dL}[34,35]$, but the extent to which this upper threshold is maintained in kidney transplant patients during routine management was unknown. Lastly, interventional studies typically report mean $\mathrm{Hb}$ values, and data relating to $\mathrm{Hb}$ fluctuation in individual kidney transplant patients are lacking.

\section{Methods}

2.1. Study Design and Conduct. This was a prospective, noninterventional, single-arm study of kidney transplant patients receiving C.E.R.A. therapy at 37 German transplant centers, which took place during the period from September 2007 to November 2011. The initial observation period of nine months was extended to 15 months, as permitted in the study protocol, in order to gather longer-term data, especially with regard to the phenomenon of $\mathrm{Hb}$ cycling.

The study was undertaken in accordance with the principles laid down in the Declaration of Helsinki and Good Clinical Practice. The study protocol was approved by the ethics committee at the Medizinische Hochschule Hannover, Hannover, Germany. All participants provided written informed consent.

2.2. Patient Population. Patients were eligible for inclusion if they had received a kidney transplant at least three months prior to study entry and had stable graft function (defined as $\leq 25 \%$ loss of function in the previous three months) and their physicians had decided to administer C.E.R.A. therapy prior to study entry. All patients were required to have a life expectancy of at least nine months (the initial planned duration of the study period), with no active malignant disease or acute infection and no acute blood loss or decrease in $\mathrm{Hb}$ level, in the four weeks prior to inclusion. Patients on dialysis were excluded. Patients were to be withdrawn from the study if they required dialysis at any point or if an ESA other than C.E.R.A. was initiated.

2.3. Medication. Prior to study entry, any ESA therapy was administered by the physician according to local practice and the summary of product characteristics of the selected ESA. All patients received C.E.R.A. therapy from study entry, prescribed according to local practice.

2.4. Evaluation. Study visits were scheduled to take place at study entry and once a month throughout the 15-month observation period, with a minimum of fifteen postbaseline visits. For patients enrolled prior to extension of the study to 15 months, a minimum of nine postbaseline visits were required. At study entry, the following data were collected: demographics, type of transplant, time since transplantation, duration and regimen of previous ESA therapy, baseline $\mathrm{Hb}$ concentration prior to C.E.R.A. administration, additional laboratory values (iron status, blood count, liver function, estimated glomerular filtration rate (eGFR), C-reactive protein (CRP) and vitamin $\mathrm{B}_{12}$ concentrations), and concomitant disease/medication. Subsequent study visits included recording of $\mathrm{Hb}$ value prior to C.E.R.A. administration, collection of additional laboratory data, and changes in concomitant disease/medication. GFR was estimated using the abbreviated four-variable Modification of Diet in Renal Disease (MDRD [36]) formula. Adverse events were documented, including duration, severity, whether the event was regarded as serious, and causal relationship with C.E.R.A. Serious adverse events were defined as those which were life-threatening or fatal, required unplanned hospitalization or prolonged hospitalization, resulted in persistent or significant disability or incapacity, or were regarded as an important medical event. Additionally, a decrease in $\mathrm{Hb}$ concentration of $>2 \mathrm{~g} / \mathrm{dL}$, any occurrence of pure red cell aplasia or production of antiepoetin antibodies was to be handled as serious adverse drug reactions of special interest. 


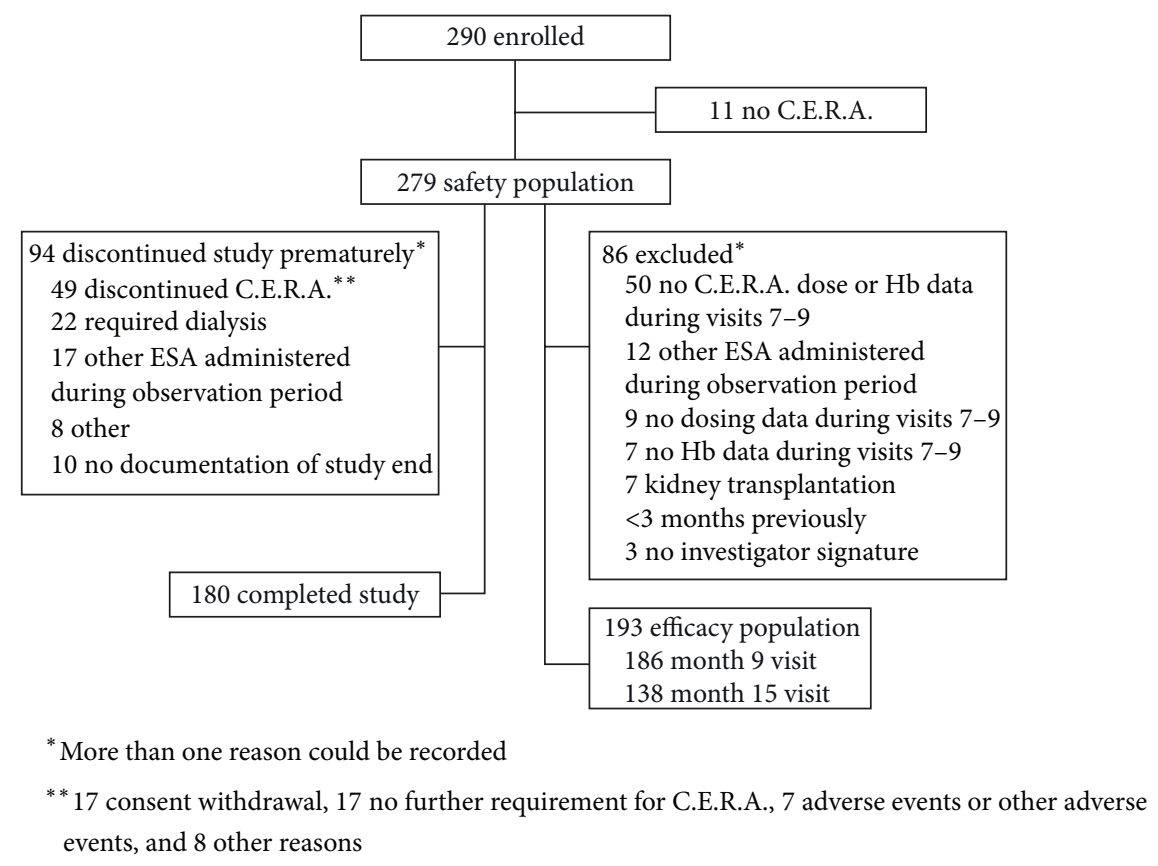

FIgure 1: Patient disposition.

Data were recorded by study investigators on printed forms and checked at the participating center for completeness, and then entered independently to a database by an independent research organization (M.A.R.C.O. GmbH \& Co KG, 40227 Düsseldorf, Germany) which was also responsible for clarifying discrepancies on the submitted forms.

2.5. Statistical Analysis. The main efficacy variable was the proportion of patients ("responders") achieving an $\mathrm{Hb}$ concentration of $11-12 \mathrm{~g} / \mathrm{dL}$ at each of visits 7,8 , and 9 , that is, after a 7-9 month period for C.E.R.A. dose titration. Following extension of the study to a 15-month observation period, the proportion of patients within each of these two $\mathrm{Hb}$ ranges was also calculated for the periods covering months 7 to 12 and months 7 to 15 . In additional prespecified analyses, the proportion of patients within the $\mathrm{Hb}$ ranges $10-12,10-13 \mathrm{~g} / \mathrm{dL}$ and $11-13 \mathrm{~g} / \mathrm{dL}$ were also calculated for each of these time periods.

The sample size calculation showed that a total of 300 patients were required, based on a maximum responder rate of $85 \%$, a mean accuracy (mean confidence interval width) of $5 \%$, a drop-out rate of approximately $30 \%$, and a significance level of 5\%. All analyses are presented descriptively. Confidence intervals are reported where appropriate. Efficacy analyses were performed in the efficacy population, defined as all patients who provided at least one measurement of $\mathrm{Hb}$ concentration and received at least one dose of C.E.R.A. during months 7-9 of the study, did not receive any ESA therapy other than C.E.R.A. during the study, met the inclusion/exclusion criteria as confirmed in writing by the investigator, and did not have other major protocol violations. Safety analyses were performed on all patients who received at least one dose of C.E.R.A. For patients in whom C.E.R.A. therapy was terminated before the end of the observation period, data were analyzed to the point of discontinuation.

\section{Results}

3.1. Patient Population. In total, 290 patients were enrolled to the study. Of these, 11 did not receive C.E.R.A. such that the safety population comprised 279 patients. The efficacy population included 193 patients, with exclusion most frequently due to absence of C.E.R.A. dosing and/or a missing $\mathrm{Hb}$ concentration during months 7-9. In total, 186 patients in the efficacy population completed month 9 and 138 completed month 15 . Ninety-four patients discontinued the study prematurely (Figure 1) and 49 stopped C.E.R.A. therapy prematurely, most frequently due to patients' request (17/49). Other frequent reasons were the requirement to start dialysis $(n=22)$ and administration of another ESA $(n=17)$ (Figure 1). The mean time between study visits was 35.3 (41.6) days.

The mean age was approximately 51 years, and approximately half the patients were male (Table 1). The mean (SD) eGFR was $35.3(16.6) \mathrm{mL} / \mathrm{min} / 1.73 \mathrm{~m}^{2}$.

Data on immunosuppressive therapy was available for only $43 / 279$ patients (15.4\%), including mycophenolic acid $(n=24)$, an mTOR inhibitor $(n=18)$, and a calcineurin inhibitor $(n=22)$.

3.2. Iron Status. Iron deficiency, defined as serum ferritin $<100 \mathrm{ng} / \mathrm{mL}$ or TSAT $<20 \%$, was present in 26 of the 126 patients for whom data were available at study entry $(20.6 \%)$. Mean (SD) serum ferritin at study entry was 198 (523) ng/mL (median $72 \mathrm{ng} / \mathrm{mL}$, interquartile range $26-179 \mathrm{ng} / \mathrm{mL}[n=$ $111]$ ), and mean (SD) TSAT was 28.3 (11.2)\% (median 28\%, 
TABLE 1: Patient demographics and baseline characteristics at study entry (safety population, $n=279$ ).

\begin{tabular}{|c|c|}
\hline Recipient age (years) & $51.1(14.1)$ \\
\hline Male recipient, $n(\%)$ & $137(49.1)$ \\
\hline Recipient body mass index $\left(\mathrm{kg} / \mathrm{m}^{2}\right)$ & $24.8(4.2)$ \\
\hline \multicolumn{2}{|l|}{ Cause of end-stage renal disease ${ }^{\mathrm{a}}, n(\%)$} \\
\hline Glomerulonephritis & $92(33.0)$ \\
\hline Polycystic kidney & $26(9.3)$ \\
\hline Chronic pyelonephritis & $25(9.0)$ \\
\hline Hypertensive nephrosclerosis & $19(6.8)$ \\
\hline Diabetic nephropathy & $15(5.4)$ \\
\hline Other & $96(34.4)$ \\
\hline Unknown & $18(6.5)$ \\
\hline Donor age (years) & $49.3(14.4)$ \\
\hline Living donor, $n(\%)$ & $54(19.4)$ \\
\hline Time since kidney transplantation (years) & $7.2(6.1)$ \\
\hline $\mathrm{Hb}(\mathrm{g} / \mathrm{dL})$ & $11.2(1.2) \mathrm{g} / \mathrm{dL}$ \\
\hline \multicolumn{2}{|l|}{ Iron supplementation, $n(\%)^{\mathrm{b}}$} \\
\hline Any & $74(26.5)$ \\
\hline Intravenous iron & $23(8.2)$ \\
\hline Oral iron & $56(20.1)$ \\
\hline Unspecified & $2(0.7)$ \\
\hline \multicolumn{2}{|l|}{ Concomitant medication, $n(\%)$} \\
\hline Mycophenolic acid & $24(8.6)^{\mathrm{c}}$ \\
\hline Calcineurin inhibitor & $22(7.9)^{\mathrm{c}}$ \\
\hline mTOR inhibitor & $18(6.5)^{\mathrm{c}}$ \\
\hline Angiotensin-converting enzyme inhibitor & $107(38.4)$ \\
\hline Angiotensin-II receptor antagonist & $95(34.1)$ \\
\hline \multicolumn{2}{|l|}{ eGFR (MDRD) at study entry, $\mathrm{mL} / \mathrm{min} / 1.73 \mathrm{~m}^{2}$} \\
\hline Mean (SD) & $35.3(16.6)$ \\
\hline Median (interquartile range) & $33.5(24.0-44.0)$ \\
\hline \multicolumn{2}{|l|}{ Serum ferritin, ng/mL } \\
\hline Mean (SD) & $198(523)$ \\
\hline Median (interquartile range) & $72(26-179)$ \\
\hline \multicolumn{2}{|l|}{ Transferrin saturation, $\%$} \\
\hline Mean (SD) & $28.3(11.2)$ \\
\hline Median (interquartile range) & $28(20-35)$ \\
\hline \multicolumn{2}{|l|}{$\mathrm{CRP}, \mathrm{mg} / \mathrm{L}$} \\
\hline Mean (SD) & $8.4(21.0)$ \\
\hline Median (interquartile range) & $3.0(1.2-6.4)$ \\
\hline \multicolumn{2}{|l|}{ Previous ESA therapy, $n(\%)$} \\
\hline None & $55(19.7)$ \\
\hline Darbepoetin alfa & $98(35.1)$ \\
\hline C.E.R.A. & $45(16.1)$ \\
\hline Epoetin beta & $61(21.9)$ \\
\hline Epoetin delta & $13(4.7)$ \\
\hline Epoetin alfa & $7(2.5)$ \\
\hline \multicolumn{2}{|l|}{ Duration of previous ESA therapy, months } \\
\hline Darbepoetin alfa & $20.2(22.3)$ \\
\hline C.E.R.A. & $3.7(3.9)$ \\
\hline Epoetin beta & $19.6(18.3)$ \\
\hline
\end{tabular}

TABle 1: Continued.

\begin{tabular}{lc}
\hline Epoetin delta & $16.5(18.7)$ \\
Epoetin alfa & $12.8(9.4)$ \\
\hline
\end{tabular}

${ }^{\mathrm{a}}$ More than one cause could be listed per patient. ${ }^{\mathrm{b}}$ More than one type could be listed per patient. ${ }^{c}$ Data on immunosuppressive therapy were provided in only 43 patients.

Continuous variables are shown as mean (SD) unless otherwise stated.

C.E.R.A.: continuous erythropoietin receptor activator; CRP: C-reactive protein; eGFR: estimated GFR; ESA: erythropoiesis stimulating agent; MDRD: Modification of Diet in Renal Disease; SD: standard deviation.

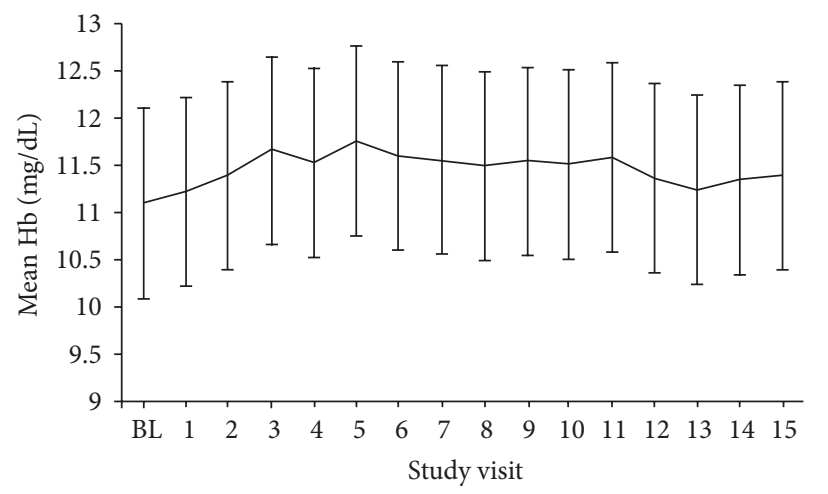

Figure 2: Hb level (efficacy population, $n=191$ ). Values are shown as mean (SD). BL: baseline.

interquartile range $20-35 \%[n=106])$. Use of iron therapy was reported in $74 / 279$ patients in the safety set $(26.5 \%)$, most frequently ferrous sulfate $(n=51)$ or iron sucrose $(n=15)$.

\subsection{Previous ESA Therapy and C.E.R.A. Administration.} Four-fifths of the population $(224 / 279,80.3 \%)$ were receiving ESA therapy at the time of study entry, most frequently darbepoetin alfa $(n=98,35.1 \%)$ or C.E.R.A. $(n=45,16.1 \%)$ (Table 1). The cohort of 45 patients previously treated with C.E.R.A. had received the drug for a mean (SD) of 3.7 (3.9) months.

C.E.R.A. was administered subcutaneously in all patients, with three patients also receiving one or more intravenous application (Table 2). The mean (SD) time between C.E.R.A. applications was 34.0 (11.9) days, and the drug was administered in the majority of cases by the patient (Table 2). The mean (SD) dose of C.E.R.A. throughout the study was 95.1 (53.2) $\mu$ g, with only a small change from the initial dose $(92.2$ [56.0] $\mu \mathrm{g})$ to the final dose $(98.8[59.5] \mu \mathrm{g})$. No dose changes were required in 119 patients $(42.7 \%)$. Among the 160 patients $(57.3 \%)$ in whom the initial C.E.R.A. dose was changed, similar proportions of patients received a dose increase or decrease (Table 2).

3.4. Efficacy. At study entry, mean (SD) $\mathrm{Hb}$ was 11.1 $(0.99) \mathrm{g} / \mathrm{dL}$ (median $11.1 \mathrm{~g} / \mathrm{dL}$, interquartile range $10.4-$ $11.8 \mathrm{~g} / \mathrm{dL}$ ) in the efficacy population. Mean $\mathrm{Hb}$ remained stable throughout the observation period, with values of 11.5 (1.1) g/dL at month 7, 11.6 (1.3) g/dL at month 9, and 11.4 (1.1) $\mathrm{g} / \mathrm{dL}$ at month 15 (Figure 2). The initial small increase in 
TABLE 2: C.E.R.A. administration (safety population, $n=279$ ).

\begin{tabular}{lc}
\hline Reason for initiation of C.E.R.A., $n(\%)^{\mathrm{a}}$ & \\
New and innovative application scheme & $173(62.2)$ \\
No previous ESA therapy & $86(30.9)$ \\
Therapeutic failure of previously used ESA & $16(5.8)$ \\
Adverse effects of previously used ESA & $2(0.7)$ \\
Other & $5(1.8)$ \\
Route of application, $n$ (\%) & \\
Subcutaneous & $260(93.2)$ \\
Subcutaneous and intravenous & $3(1.1)$ \\
Unknown & $16(5.7)$ \\
Application by, $n$ (\%) & $180(64.5)$ \\
Patient & $1(0.4)$ \\
Patient or nurse & $28(10.0)$ \\
Physician & $69(24.7)$ \\
Physician or patient & $1(0.4)$ \\
Physician or patient or nurse & \\
C.E.R.A. dose per application, $\mu$ g & \\
Initial dose & $92.2(56.0)$ \\
$\quad$ Mean (SD) & $75.0(30-360)$ \\
Median (range) & \\
Final dose, mean (SD) & $119(42.7)$ \\
$\quad$ Mean (SD) & $160(57.3)$ \\
Median (range) & $117(41.9)$ \\
Throughout study & $132(47.3)$ \\
$\quad$ Mean (SD) & \\
Median (range) & $34.8(59.5)$ \\
Time between C.E.R.A. applications, days & \\
Mean (SD) & \\
Median (range) & \\
Any dose increase & \\
No dose change & \\
Any dose change & \\
\hline
\end{tabular}

C.E.R.A.: continuous erythropoietin receptor activator; SD: standard deviation.

${ }^{\mathrm{a}}$ More than one reason could be selected from a preprinted list.

$\mathrm{Hb}$ values during the first three months of the observation period was largely accounted for by initiation of C.E.R.A. in the 55 patients who were ESA-naive at study entry, in whom mean (SD) Hb increased from $10.8(0.8) \mathrm{g} / \mathrm{dL}$ at baseline to $11.5(1.0) \mathrm{g} / \mathrm{dL}$ at month 3.

No difference in mean baseline $\mathrm{Hb}$ values was observed when patients were stratified according to eGFR at study entry. In patients with baseline eGFR $<30 \mathrm{~mL} / \mathrm{min} / 1.73 \mathrm{~m}^{2}$, mean (SD) Hb was $11.1(1.2) \mathrm{g} / \mathrm{dL}(n / N=42 / 193) \mathrm{com}-$ pared to $11.2(0.9) \mathrm{g} / \mathrm{dL}$ for patients with baseline eGFR 30$60 \mathrm{~mL} / \mathrm{min} / 1.73 \mathrm{~m}^{2}$.

At study entry, $11.8 \%(21 / 178)$ had an $\mathrm{Hb}$ value $<10 \mathrm{~g} / \mathrm{dL}$ and $3.4 \%(6 / 178)$ had an $\mathrm{Hb}$ value $>13 \mathrm{~g} / \mathrm{dL}$. At months 7 , 9 , and 15 , respectively, $9.9 \%$ (14/142), $10.6 \%$ (15/142), and $8.6 \%(9 / 105)$ had an $\mathrm{Hb}$ level < $10 \mathrm{~g} / \mathrm{dL}$, while $12.7 \%(18 / 142)$,
$13.4 \%(19 / 142)$, and 7.6\% (8/105) had an Hb level > $13 \mathrm{~g} / \mathrm{dL}$. At all times points during the study, no more than $15 \%$ of patients had an $\mathrm{Hb}$ level $\geq 13 \mathrm{~g} / \mathrm{dL}$. During the prespecified evaluation period (visits 7-9), 20.7\% of patients (40/193) had all $\mathrm{Hb}$ values within the range $11-12 \mathrm{~g} / \mathrm{dL}$, increasing to $64.8 \%$ for the wider range of $10-13 \mathrm{~g} / \mathrm{dL}$ (Table 3 ). As would be expected, the proportion of patients with all $\mathrm{Hb}$ within target ranges declined as the period was extended to months 7-12 and 7-15 (Table 3). The mean (SD) deviation in $\mathrm{Hb}$ values from the intraindividual mean was $0.50(0.6) \mathrm{g} / \mathrm{dL}$ during the evaluation period (visit 7-9), $1.0(0.6) \mathrm{g} / \mathrm{dL}$ for the period visits $7-12$, and $1.2(0.6) \mathrm{g} / \mathrm{dL}$ for the period visits $7-15$. During the evaluation period, the majority of patients $(87.0 \%)$ showed a mean deviation of $\leq 1 \mathrm{~g} / \mathrm{dL}$ in $\mathrm{Hb}$ values from the intraindividual mean (Table 4).

3.5. Safety. In total, 55 patients $(19.7 \%)$ reported a total of 178 adverse events during the study. These included headache in two patients $(0.7 \%)$ and hypertension in three patients (1.1\%) (see Supplementary Table 1 in Supplementary Material available online at http://dx.doi.org/10.1155/2014/179705). Ten adverse events in seven patients $(2.5 \%)$ were considered by the investigator to be possibly, probably, or definitely related to C.E.R.A. These were hemolytic anemia, pancytopenia, thrombocytopenia, angina pectoris, unstable angina, deep vein thrombosis, hypertension (three patients), and injection site pain. Serious adverse events were reported in 32 patients (11.5\%), with four out of 59 events having at least a possible relation with C.E.R.A. (angina pectoris, unstable angina, deep vein thrombosis, and hypertension in one patient each). C.E.R.A. treatment was discontinued in three patients due to adverse events (hypertension; bone marrow depression; pancytopenia with hemolytic anemia) and in four patients due to serious adverse events (dialysis; sepsis with pneumonia, hemodialysis and renal failure; hypertension with angina pectoris; decreased hemoglobin with increased CRP).

There were four deaths during the study, none of which had a suspected relation with C.E.R.A. administration.

Mean (SD) eGFR remained unchanged during the study (study entry, $35.3[16.6] \mathrm{mL} / \mathrm{min} / 1.73 \mathrm{~m}^{2}$; month $15,34.4$ [19.8] $\mathrm{mL} / \mathrm{min} / 1.73 \mathrm{~m}^{2}$ ). No consistent pattern of change in serum ferritin concentration or TSAT was observed over the study period. Abnormal erythrocyte counts, as identified by the physician as a clinical deviation from the normal, were reported in $46.7 \%$ of patients at the prestudy visit, $24.4 \%$ at visit 9 , and $23.8 \%$ at visit 15 . No difference in the rates of clinically significant abnormalities for leukocyte or thrombocyte counts was observed during the study versus prestudy. Other laboratory values including CRP, vitamin $\mathrm{B}_{12}$, and liver enzymes showed no clinically relevant changes during the study. Mean blood pressure remained unchanged from baseline (132/77 $\mathrm{mmHg}$ ) to month 15 (130/77 $\mathrm{mmHg})$.

\section{Discussion}

In this observational study of maintenance kidney transplant patients with stable graft function, C.E.R.A. administered once a month according to local practice achieved a high 
TABle 3: Proportion of patients within $\mathrm{Hb}$ target ranges (efficacy population).

\begin{tabular}{lccr}
\hline Hb range & & Visit window & $7-15$ \\
\hline $11-12 \mathrm{~g} / \mathrm{dL}$ & $7-9^{\mathrm{a}}$ & $7-12$ & $0.0 \%(0 / 153)$ \\
$11-13 \mathrm{~g} / \mathrm{dL}$ & $20.7 \%(40 / 193)$ & $2.9 \%(4 / 137)$ & $15.0 \%(23 / 153)$ \\
$10-12 \mathrm{~g} / \mathrm{dL}$ & $40.4 \%(78 / 193)$ & $21.2 \%(29 / 137)$ & $14.4 \%(22 / 153)$ \\
$10-13 \mathrm{~g} / \mathrm{dL}$ & $42.0 \%(81 / 193)$ & $24.1 \%(33 / 137)$ & $43.1 \%(66 / 153)$ \\
\hline
\end{tabular}

${ }^{a}$ Prespecified evaluation period.

TABLE 4: Deviation of $\mathrm{Hb}$ from intraindividual mean values.

\begin{tabular}{lccr}
\hline Deviation & & Visit window & $7-15$ \\
\hline$\leq 1 \mathrm{~g} / \mathrm{dL}$ & $7-9^{\mathrm{a}}$ & $7-12$ & $41.8 \%(64 / 153)$ \\
$>1$ to $2 \mathrm{~g} / \mathrm{dL}$ & $87.0 \%(168 / 193)$ & $57.7 \%(79 / 137)$ & $45.8 \%(70 / 153)$ \\
$>2 \mathrm{~g} / \mathrm{dL}$ & $9.3 \%(18 / 193)$ & $32.8 \%(45 / 137)$ & $12.4 \%(19 / 153)$ \\
\hline
\end{tabular}

${ }^{\text {a }}$ Prespecified evaluation period.

Calculations are based on maximum deviation from individual mean values.

degree of Hb stability. The main efficacy variable, Hb concentration of $11-12 \mathrm{~g} / \mathrm{dL}$ at each of the visits at months 7,8 , and 9, was achieved by $20.7 \%$ of patients. During the evaluation period, the intrapatient $\mathrm{Hb}$ level varied by no more than $1 \mathrm{~g} / \mathrm{dL}$ in $87 \%$ of patients. Hb stability was achieved with a mean time between C.E.R.A. applications of 34 days and with patients self-administering at least some injections in $90 \%$ of cases. Moreover, $43 \%$ of patients required no change in C.E.R.A. dose throughout the study.

After a small early increase in mean $\mathrm{Hb}$ accounted for by C.E.R.A. initiation in the subgroup of patients who were ESAnaïve at study entry, mean $\mathrm{Hb}$ remained stable throughout the 15-month observation period. The finding that one in five patients maintained an $\mathrm{Hb}$ concentration in the range $11-12 \mathrm{~g} / \mathrm{dL}$ at months 7,8 , and 9 was consistent with the results of observational studies of C.E.R.A. therapy in patients receiving hemodialysis [37] or peritoneal dialysis [38]. These have reported $\mathrm{Hb}$ levels within the $11-12 \mathrm{~g} / \mathrm{dL}$ window at all three evaluation visits in $15.6 \%$ and $18.4 \%$ of patients, respectively. These findings should be interpreted against the background of a naturally high degree of $\mathrm{Hb}$ variability in patients with CKD $[39,40]$. Indeed, it has been shown that the mean within-patient variability is greater than $1 \mathrm{~g} / \mathrm{dL}$ in CKD patients receiving ESA therapy [40, 41]. Comparisons of $\mathrm{Hb}$ stability between the current results and randomized trials of ESA therapies are not clinically relevant since this observational study applied no exclusion criteria for $\mathrm{Hb}$ cycling prior to inclusion, in contrast to controlled trials which have typically excluded patients with $\mathrm{Hb}$ fluctuation $>1 \mathrm{~g} / \mathrm{dL}$ during screening [34, 42-44].

One previous study, AnemiaTrans, has examined the use of C.E.R.A. in kidney transplant recipients [45]. AnemiaTrans was a retrospective, multicenter study which included both de novo patients $(n=32)$ and maintenance patients $(n=286)$. As in the current study, the majority of maintenance patients were converted from another ESA therapy to C.E.R.A. Hb levels were monitored for six months from the time of conversion, and consistent with our results, the proportion of patients within the target $\mathrm{Hb}$ range of $11-13 \mathrm{~g} / \mathrm{dL}$ was similar at baseline and at month 6 . In the majority of converted patients $(52.5 \%), \mathrm{Hb}$ level fluctuated by less than $1 \mathrm{~g} / \mathrm{dL}$ between baseline and month 6 . The mean C.E.R.A. dose at month $6(93 \mu \mathrm{g})$ was remarkably similar to that used in our population $(95.1 \mu \mathrm{g})$. The findings of AnemiaTrans, although retrospective, support those of the present study.

The Kidney Disease: Improving Global Outcomes (KDIGO) guidelines for the care of kidney transplant recipients recommend that anemia in kidney transplant patients should be monitored and treated in the same way as patients with CKD [46]. Regular monitoring of Hb levels is mandatory for all recipients [46], but certain subpopulations are at particular risk of anemia. As in the nontransplant population, poor renal function is the strongest predictor $[1,4,6]$, but low iron stores $[1,4,6]$, probably female gender $[4,6,47]$, increasing recipient age $[4,6,33]$, donor age [1], poor nutrition, and chronic inflammation [48] also appear to contribute, exacerbated by frequent use of renin-angiotensin-aldosterone system inhibitors [3, 46]. The risk of anemia following transplantation is compounded by immunosuppression with mTOR inhibitors [46, 49-51] or mycophenolic acid $[46,52,53]$, although this effect is less marked in the presence of higher GFR [54]. Modification of the immunosuppressive regimen to ameliorate anemia should be considered but may be difficult [46], so management focuses on ESA and iron therapy after exclusion of other causes. A more cautious approach to excess ESA dosing has been adopted since randomized trials in CKD populations indicated an increased risk of stroke and venous thromboembolism when ESA therapy is used to target high $\mathrm{Hb}$ levels [22-24], especially in relatively unresponsive patients $[55,56]$. In kidney transplantation, a large retrospective study has demonstrated that reaching an $\mathrm{Hb}$ level of $14.0 \mathrm{~g} / \mathrm{dL}$ during ESA therapy is associated with increased mortality compared to $12.5 \mathrm{~g} / \mathrm{dL}$ [21]. In the current study, fewer than $15 \%$ of patients had an $\mathrm{Hb}$ level $>13 \mathrm{~g} / \mathrm{dL}$ at any time point during C.E.R.A. administration. 
The recent KDIGO Clinical Practice Guideline for Anemia in Chronic Kidney Disease advises that iron deficiency should be addressed prior to initiation of ESA therapy [57]. In our cohort of patients, the documented use of iron supplementation was low (21.5\%), but unfortunately medication reporting and the assessment of iron status seem unlikely to have been comprehensive or fell outside the prespecified windows for study visits. For example, immunosuppressive agents were listed by investigators in only $15 \%$ of patients, another clear limitation of the study. Serum ferritin levels, however, indicated the presence of low iron stores in many patients with available data, with median values consistently below the lower recommended limit of $100 \mathrm{ng} / \mathrm{mL}$ [32]. Additionally, approximately $25 \%$ of patients were below the recommended minimum TSAT level of $20 \%$ [32], a level frequently considered to represent functional iron deficiency. While data are incomplete, it appears that iron indices are not routinely monitored or managed at all centers. Thus, our observational study has identified some marked areas of concern where there is room for improvement in patient management, upon which future studies should focus.

Adverse events and serious events judged by the investigator to have at least a possible relation to C.E.R.A. were reported in $2.5 \%$ and $1.4 \%$ of patients, respectively. Taking into account the comorbidities and multiple concomitant medications given to kidney transplant patients, it is difficult to accurately assign causality to a specific drug. Of the expected adverse events listed in the summary of product characteristics for C.E.R.A., only headache $(0.70 \%)$ and hypertension $(1.10 \%)$ were observed, with hypertension contributing to discontinuation in two cases. There were no hematological or biochemical concerns.

An observational study design was chosen to document "real-world" outcomes when patients were selected for C.E.R.A. therapy and managed according to local center practice at a large number of transplant centers. Randomized trials in dialysis-dependent and nondialysis CKD populations have previously shown $\mathrm{Hb}$ control to be similar with oncemonth C.E.R.A. versus more frequent dosing with epoetin or darbepoetin $[43,58,59]$, therefore a control arm was not included. It is important to point out that it was neither the aim of this study to demonstrate the efficacy of C.E.R.A., which is already well documented, nor was the goal to compare efficacy between different ESA therapies. The main objective was to gather observational data on $\mathrm{Hb}$ fluctuation and C.E.R.A. use in transplanted patients in a real-life setting, which could be used for the development of future interventional trials in this population. Our observational study results provide a basis for future interventional trials of ESA therapy in this population. Given the presence of inadequate iron stores in a substantial proportion of patients future observational studies could benefit from a protocol-stipulated iron supplementation.

\section{Conclusion}

This observational study provides an insight into the use of C.E.R.A. therapy to treat anemia under real-life conditions in a population of stable kidney transplant patients with minimal selection criteria. Once-monthly administration, largely self-administered, achieved stable $\mathrm{Hb}$ levels with few dose medications and good tolerability. A once-monthly regimen for ESA therapy may be particularly attractive to transplant recipients who no longer have to attend frequent hemodialysis sessions and are keen to return to a normal lifestyle.

\section{Conflict of Interests}

Klemens Budde has consultancy agreements with BristolMyers Squibb, Veloxis Pharma, Novartis Pharma, Effimune Pharma, and Pfizer and has received research grants for clinical studies, speaker's fees, honoraria, travel expenses, and payment for development of educational presentations from AiCuris, Astellas, Bristol-Myers Squibb, Hexal, Veloxis Pharma, Chiesi, and Novartis Pharma; Siemens, Fresenius, Gambro, Roche AG, and Pfizer; Thomas Rath has no conflicts to declare. Volker Kliem has received research grants for clinical studies, speaker's fees, honoraria, travel expenses, and payment for educational presentations from Astellas, BristolMyers Squibb, Genzyme, Novartis Pharma, Pfizer, and Roche AG.

\section{Authors' Contribution}

All authors recruited patients, collected data, reviewed and approved the paper, and gave approval for submission.

\section{Acknowledgments}

The authors gratefully acknowledge the contribution of all study investigators: Vitomir Bajewski, Bielefeld; Volker Kliem, Hann. Münden; Hauke Salto, Peine; Anke Schwarz, Hannover; Eike Wrenger, Langenhagen; Samih Al Sarraf, Augsburg; Friederike Arenz, Emmering; Joachim Leicht, Schwandorf; Nadim Abdul-Rahmann, Magdeburg; Klemens Budde, Berlin; Erika Eger, Berlin; Markus Van der Giet, Berlin; Jan Hörstrup, Berlin; Petra Reinke, Berlin; Stefan Degenhardt, Viersen; Frank Dellanna, Düsseldorf; Thomas Gerhardt, Bonn; Bernd Krumme, Wiesbaden; Joachim Lippert, Cochem; Ulrich Münch, Düsseldorf; Thomas Rath, Kaiserlautern; Olaf Rettkowski, Halle; Sabine Weinmeister, Erfurt; Klaus Bischoff, Heppenheim; Alfred Bosch, Worms; Frank Leistikow, Mannheim; Michael Schömig, Heilbronn; Rainer Schürger, Neckarsulm; Wolfgang Backs, Hamburg; Tilmann David-Walek, Kiel; Thomas Gliesche, Güstrow; Joachim Gloy, Hamburg; Ingo Krenz, Hamburg; Ann Michelsen, Rostock; Andrea Mitzner, Rostock; Ralf Schmidt, Osnabrück; Franz Zantvoort, Bremen; Kai Hahn, Dortmund; Steffen Hengst, Stefan Zinn, Alsfeld; Dorothee Hoffacker, Duisburg; Klaus Kalb, Lüdenscheid; Schirin Kamali-Ernst, Wetzlar; Thomas Klein, Limburg; Johann Knee, Essen; Fabrice Renner, Giessen; Barbara Suwelack, Münster; André Voßkühler, Bottrop. The study was supported by Roche Pharma AG, Germany. 


\section{References}

[1] R. Poesen, B. Bammens, K. Claes et al., "Prevalence and determinants of anemia in the immediate postkidney transplant period," Transplant International, vol. 24, no. 12, pp. 1208-1215, 2011.

[2] A. J. Erslev and A. Besarab, "Erythropoietin in the pathogenesis and treatment of the anemia of chronic renal failure," Kidney International, vol. 51, no. 3, pp. 622-630, 1997.

[3] J. M. Yabu and W. C. Winkelmayer, "Posttransplantation anemia: mechanisms and management," Clinical Journal of the American Society of Nephrology, vol. 6, no. 7, pp. 1794-1801, 2011.

[4] N. Shah, S. Al-Khoury, B. Afzali et al., "Posttransplantation anemia in adult renal allograft recipients: prevalence and predictors," Transplantation, vol. 81, no. 8, pp. 1112-1118, 2006.

[5] H. Joist, D. C. Brennan, and D. W. Coyne, "Anemia in the kidney-transplant patient," Advances in Chronic Kidney Disease, vol. 13, no. 1, pp. 4-10, 2006.

[6] M. Z. Molnar, I. Mucsi, I. C. Macdougall et al., "Prevalence and management of anaemia in renal transplant recipients: data from ten European centres," Nephron Clinical Practice, vol. 117, no. 2, pp. c127-c134, 2011.

[7] M. Z. Molnar, M. Novak, C. Ambrus et al., "Anemia in kidney transplanted patients," Clinical Transplantation, vol. 19, no. 6, pp. 825-833, 2005.

[8] A. Turkowski-Duhem, N. Kamar, O. Cointault et al., "Predictive factors of anemia within the first year post renal transplant," Transplantation, vol. 80, no. 7, pp. 903-909, 2005.

[9] A. Kolonko, J. Pinocy-Mańdok, M. Kocierz et al., "Anemia and erythrocytosis after kidney transplantation: a 5-year graft function and survival analysis," Transplantation Proceedings, vol. 41, no. 8, pp. 3046-3051, 2009.

[10] S. Fishbane, "Anemia and cardiovascular risk in the patient with kidney disease," Heart Failure Clinics, vol. 4, no. 4, pp. 401-410, 2008.

[11] M. L. Thorp, E. S. Johnson, X. Yang, A. F. Petrik, R. Platt, and D. H. Smith, "Effect of anaemia on mortality, cardiovascular hospitalizations and end-stage renal disease among patients with chronic kidney disease," Nephrology, vol. 14, no. 2, pp. 240246, 2009.

[12] C. P. Kovesdy, B. K. Trivedi, K. Kalantar-Zadeh, and J. E. Anderson, "Association of anemia with outcomes in men with moderate and severe chronic kidney disease," Kidney International, vol. 69, no. 3, pp. 560-564, 2006.

[13] T. C. Dowling, "Prevalence, etiology, and consequences of anemia and clinical and economic benefits of anemia correction in patients with chronic kidney disease: an overview," American Journal of Health-System Pharmacy, vol. 64, no. 13, supplement 8, pp. S3-S7, 2007.

[14] N. Kamar, L. Rostaing, S. Ignace, and E. Villar, "Impact of posttransplant anemia on patient and graft survival rates after kidney transplantation: a meta-analysis," Clinical Transplantation, vol. 26, no. 3, pp. 461-469, 2012.

[15] L. G. de Andrade, J. M. Abrão, and M. F. Carvalho, "Anemia at one year is an independent risk factor of graft survival," International Urology and Nephrology, vol. 44, no. 1, pp. 263-268, 2012.

[16] D. Chhabra, M. Grafals, A. I. Skaro, M. Parker, and L. Gallon, "Impact of anemia after renal transplantation on patient and graft survival and on rate of acute rejection," Clinical Journal of the American Society of Nephrology, vol. 3, no. 4, pp. 1168-1174, 2008.
[17] M. Z. Molnar, M. Czira, C. Ambrus et al., "Anemia is associated with mortality in kidney-transplanted patients-a prospective cohort study," American Journal of Transplantation, vol. 7, no. 4, pp. 818-824, 2007.

[18] A. Djamali, Y. T. Becker, W. D. Simmons, C. A. Johnson, N. Premasathian, and B. N. Becker, "Increasing hematocrit reduces early posttransplant cardiovascular risk in diabetic transplant recipients," Transplantation, vol. 76, no. 5, pp. 816-820, 2003.

[19] W. C. Winkelmayer, A. Chandraker, M. Alan Brookhart, R. Kramar, and G. Sunder-Plassmann, "A prospective study of anaemia and long-term outcomes in kidney transplant recipients," Nephrology Dialysis Transplantation, vol. 21, no. 12, pp. 3559-3566, 2006.

[20] Y. Vanrenterghem, C. Ponticelli, J. M. Morales et al., "Prevalence and management of anemia in renal transplant recipients: a European survey," American Journal of Transplantation, vol. 3, no. 7, pp. 835-845, 2003.

[21] G. Heinze, A. Kainz, W. H. Hörl, and R. Oberbauer, "Mortality in renal transplant recipients given erythropoietins to increase haemoglobin concentration: cohort study," British Medical Journal, vol. 339, article b4018, 2009.

[22] M. A. Pfeffer, E. A. Burdmann, C.-Y. Chen et al., "A trial of darbepoetin alfa in type 2 diabetes and chronic kidney disease," The New England Journal of Medicine, vol. 361, no. 21, pp. 20192032, 2009.

[23] A. K. Singh, L. Szczech, K. L. Tang et al., "Correction of anemia with epoetin alfa in chronic kidney disease," The New England Journal of Medicine, vol. 355, no. 20, pp. 2085-2098, 2006.

[24] T. B. Drüeke, F. Locatelli, N. Clyne et al., "Normalization of hemoglobin level in patients with chronic kidney disease and anemia," The New England Journal of Medicine, vol. 355, no. 20, pp. 2071-2084, 2006.

[25] A. van Loo, R. Vanholder, P. Bernaert, J. de Roose, and N. Lameire, "Recombinant human erythropoietin corrects anaemia during the first weeks after renal transplantation: a randomized prospective study," Nephrology Dialysis Transplantation, vol. 11, no. 9, pp. 1815-1821, 1996.

[26] W. van Biesen, R. Vanholder, N. Veys, F. Verbeke, and N. Lameire, "Efficacy of erythropoietin administration in the treatment of anemia immediately after renal transplantation," Transplantation, vol. 79, no. 3, pp. 367-368, 2005.

[27] R. D. Bloom, P. Bolin, S. R. Gandra, D. Scarlata, and J. Petersen, "Impact on health-related quality of life in kidney transplant recipients with late posttransplant anemia administered darbepoetin alfa: results from the strata study," Transplantation Proceedings, vol. 43, no. 5, pp. 1593-1600, 2011.

[28] D. Ribes, N. Kamar, J. Guitard, L. Esposito, and L. Rostaing, "Darbepoetin-alfa in renal-transplant patients: an observational monocentric study," Clinical Nephrology, vol. 69, no. 2, pp. 102-106, 2008.

[29] L. M. McDevitt, L. D. Smith, K. T. Somerville, J. L. Corbett, and F. S. Shihab, "A retrospective assessment of pre-treatment variables on the response to darbepoetin alfa after renal transplantation," American Journal of Transplantation, vol. 5, no. 8, pp. 1948-1956, 2005.

[30] N. Muirhead, D. C. Cattran, J. Zaltzman et al., "Safety and efficacy of recombinant human erythropoietin in correcting the anemia of patients with chronic renal allograft dysfunction," Journal of the American Society of Nephrology, vol. 5, no. 5, pp. 1216-1222, 1994. 
[31] National Kidney Foundation, "KDOQI clinical practice guidelines and clinical practice recommendations for anemia in chronic kidney disease," American Journal of Kidney Diseases, vol. 47, no. 5, supplement 3, pp. S1-S146, 2006.

[32] I. C. Macdougall, R. Robson, S. Opatrná et al., "Pharmacokinetics and pharmacodynamics of intravenous and subcutaneous continuous erythropoietin receptor activator (C.E.R.A.) in patients with chronic kidney disease," Clinical Journal of the American Society of Nephrology, vol. 1, no. 6, pp. 1211-1215, 2006.

[33] F. Locatelli, A. Covic, K.-U. Eckardt, A. Wiecek, and R. Vanholder, "Anaemia management in patients with chronic kidney disease: a position statement by the Anaemia Working Group of European Renal Best Practice (ERBP)," Nephrology Dialysis Transplantation, vol. 24, no. 2, pp. 348-354, 2009.

[34] B. Canaud, G. Mingardi, J. Braun et al., "Intravenous C.E.R.A. maintains stable haemoglobin levels in patients on dialysis previously treated with darbepoetin alfa: results from STRIATA, a randomized phase III study," Nephrology Dialysis Transplantation, vol. 23, no. 11, pp. 3654-3661, 2008.

[35] I. C. Macdougall, R. Walker, R. Provenzano et al., "C.E.R.A corrects anemia in patients with chronic kidney disease not on dialysis: results of a randomized clinical trial," Clinical Journal of the American Society of Nephrology, vol. 3, no. 2, pp. 337-347, 2008.

[36] E. D. Poggio, X. Wang, D. M. Weinstein et al., "Assessing glomerular filtration rate by estimation equations in kidney transplant recipients," American Journal of Transplantation, vol. 6, no. 1, pp. 100-108, 2006.

[37] T. Weinreich, F. Leistikow, H.-G. Hartmann et al., "Monthly continuous erythropoietin receptor activator treatment maintains stable hemoglobin levels in routine clinical management of hemodialysis patients," Hemodialysis International, vol. 16, no. 1, pp. 11-19, 2012.

[38] M. Koch, W. Treiber, and D. Fliser, "Effective achievement of hemoglobin stability with once-monthly C.E.R.A. in peritoneal dialysis patients: a prospective study," Clinical Drug Investigation, vol. 33, no. 10, pp. 699-706, 2013.

[39] S. Fishbane and J. S. Berns, "Hemoglobin cycling in hemodialysis patients treated with recombinant human erythropoietin," Kidney International, vol. 68, no. 3, pp. 1337-1343, 2005.

[40] K. van der Putten, F. H. van der Baan, H. Schellekens, and C. A. J. M. Gaillard, "Hemoglobin variability in patients with chronic kidney disease in the Netherlands," International Journal of Artificial Organs, vol. 32, no. 11, pp. 787-793, 2009.

[41] V. Agrawal, S. Mukherjee, R. Kosuri, and F. Dumler, "Anemia management with darbepoetin-alfa in outpatient hemodialysis patients switched from epoetin-alfa: a community hospital experience," American Journal of Therapeutics, vol. 17, no. 5, pp. 469-475, 2010.

[42] N. W. Levin, S. Fishbane, F. V. Cañedo et al., "Intravenous methoxy polyethylene glycol-epoetin beta for haemoglobin control in patients with chronic kidney disease who are on dialysis: a randomised non-inferiority trial (MAXIMA)," The Lancet, vol. 370, no. 9596, pp. 1415-1421, 2007.

[43] W. Sulowicz, F. Locatelli, J.-P. Ryckelynck et al., "Once-monthly subcutaneous C.E.R.A. maintains stable hemoglobin control in patients with chronic kidney disease on dialysis and converted directly from epoetin one to three times weekly," Clinical Journal of the American Society of Nephrology, vol. 2, no. 4, pp. 637-646, 2007.
[44] B. Spinowitz, D. W. Coyne, C. E. Lok et al., "C.E.R.A. maintains stable control of hemoglobin in patients with chronic kidney disease on dialysis when administered once every two weeks," American Journal of Nephrology, vol. 28, no. 2, pp. 280-289, 2008.

[45] A. I. Sánchez-Fructuoso, J. C. Ruiz, J. V. Torregrosa et al., "Anemia control in renal transplant recipients receiving continuous erythropoietin receptor activator (C.E.R.A.) treatment: the AnemiaTrans Study," Advances in Therapy, vol. 29, no. 11, pp. 979-991, 2012.

[46] Kidney Disease: Improving Global Outcomes (KDIGO) Transplant Work Group, "KDIGO clinical practice guideline for the care of kidney transplant recipients," American Journal of Transplantation, vol. 9, supplement 3, pp. S1-S155, 2009.

[47] S. J. Chadban, L. Baines, K. Polkinghorne et al., "Anemia after kidney transplantation is not completely explained by reduced kidney function," American Journal of Kidney Diseases, vol. 49, no. 2, pp. 301-309, 2007.

[48] M. Z. Molnar, M. E. Czira, A. Rudas et al., "Association between the malnutrition-inflammation score and post-transplant anaemia," Nephrology Dialysis Transplantation, vol. 26, no. 6, pp. 2000-2006, 2011.

[49] S. Fishbane, D. J. Cohen, D. W. Coyne, A. Djamali, A. K. Singh, and J. B. Wish, "Posttransplant anemia: the role of sirolimus," Kidney International, vol. 76, no. 4, pp. 376-382, 2009.

[50] H. Ekberg, C. Bernasconi, J. Nöldeke et al., "Cyclosporine, tacrolimus and sirolimus retain their distinct toxicity profiles despite low doses in the Symphony study," Nephrology Dialysis Transplantation, vol. 25, no. 6, pp. 2004-2010, 2010.

[51] A. C. Webster, V. W. S. Lee, J. R. Chapman, and J. C. Craig, “Target of rapamycin inhibitors (sirolimus and everolimus) for primary immunosuppression of kidney transplant recipients: a systematic review and meta-analysis of randomized trials," Transplantation, vol. 81, no. 9, pp. 1234-1248, 2006.

[52] D. R. J. Kuypers, H. de Jonge, M. Naesens et al., "Current target ranges of mycophenolic acid exposure and drug-related adverse events: a 5-year, open-label, prospective, clinical follow-up study in renal allograft recipients," Clinical Therapeutics, vol. 30, no. 4, pp. 673-683, 2008.

[53] "Mycophenolate mofetil in renal transplantation: 3-year results from the placebo-controlled trial. European Mycophenolate Mofetil Cooperative Study Group," Transplantation, vol. 68, no. 3, pp. 391-396, 1999.

[54] P. Friend, G. Russ, R. Oberbauer et al., "Incidence of anemia in sirolimus-treated renal transplant recipients: the importance of preserving renal function," Transplant International, vol. 20, no. 9, pp. 754-760, 2007.

[55] L. A. Szczech, H. X. Barnhart, J. K. Inrig et al., "Secondary analysis of the CHOIR trial epoetin- $\alpha$ dose and achieved hemoglobin outcomes," Kidney International, vol. 74, no. 6, pp. 791798, 2008.

[56] S. D. Solomon, H. Uno, E. F. Lewis et al., "Erythropoietic response and outcomes in kidney disease and type 2 diabetes," The New England Journal of Medicine, vol. 363, no. 12, pp. 1146$1155,2010$.

[57] Kidney Disease Improving Global Outcomes (KDIGO), "Clinical practice guideline for anemia in chronic kidney disease," Kidney International Supplements, vol. 2, no. 4, pp. 292-298, 2012. 
[58] F. Locatelli, G. Villa, A. L. M. de Francisco et al., "Effect of a continuous erythropoietin receptor activator (C.E.R.A.) on stable haemoglobin in patients with $\mathrm{CKD}$ on dialysis: once monthly administration," Current Medical Research and Opinion, vol. 23, no. 5, pp. 969-979, 2007.

[59] S. D. Roger, F. Locatelli, R. P. Woitas et al., "C.E.R.A. once every 4 weeks corrects anaemia and maintains haemoglobin in patients with chronic kidney disease not on dialysis," Nephrology Dialysis Transplantation, vol. 26, no. 12, pp. 3980-3986, 2011. 


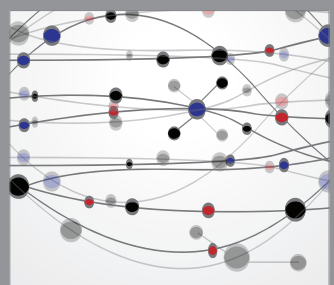

The Scientific World Journal
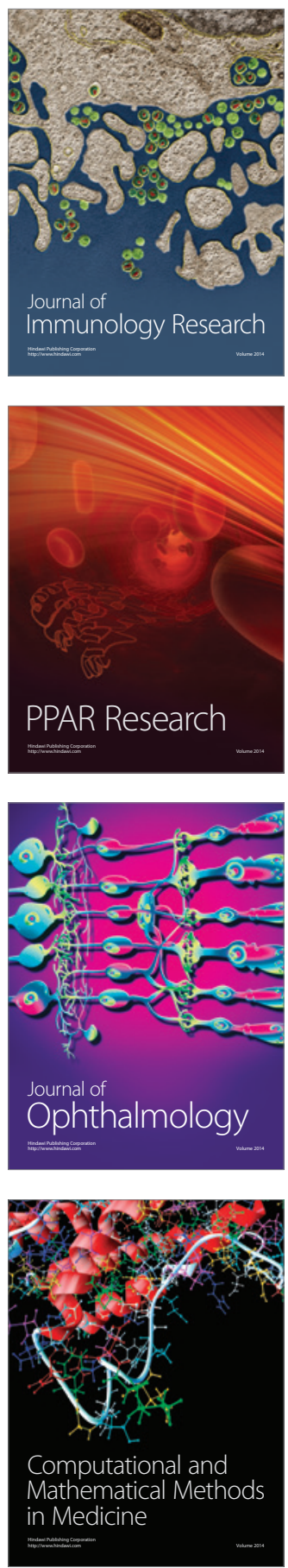

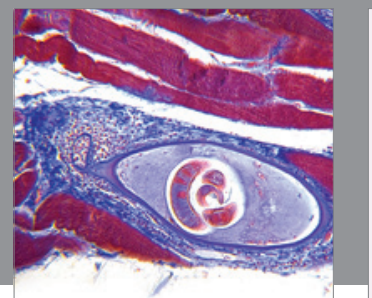

Gastroenterology

Research and Practice
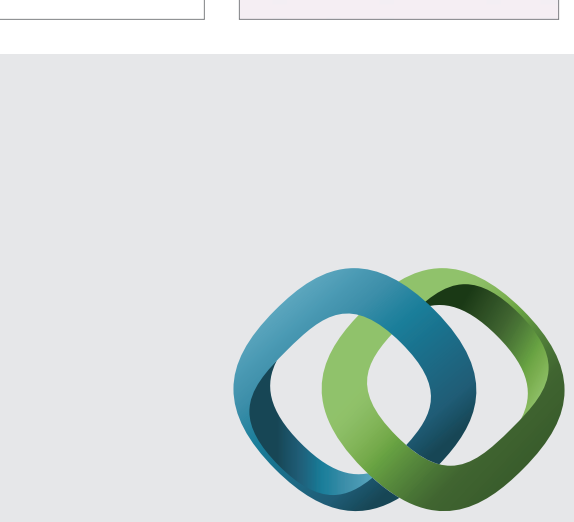

\section{Hindawi}

Submit your manuscripts at

http://www.hindawi.com
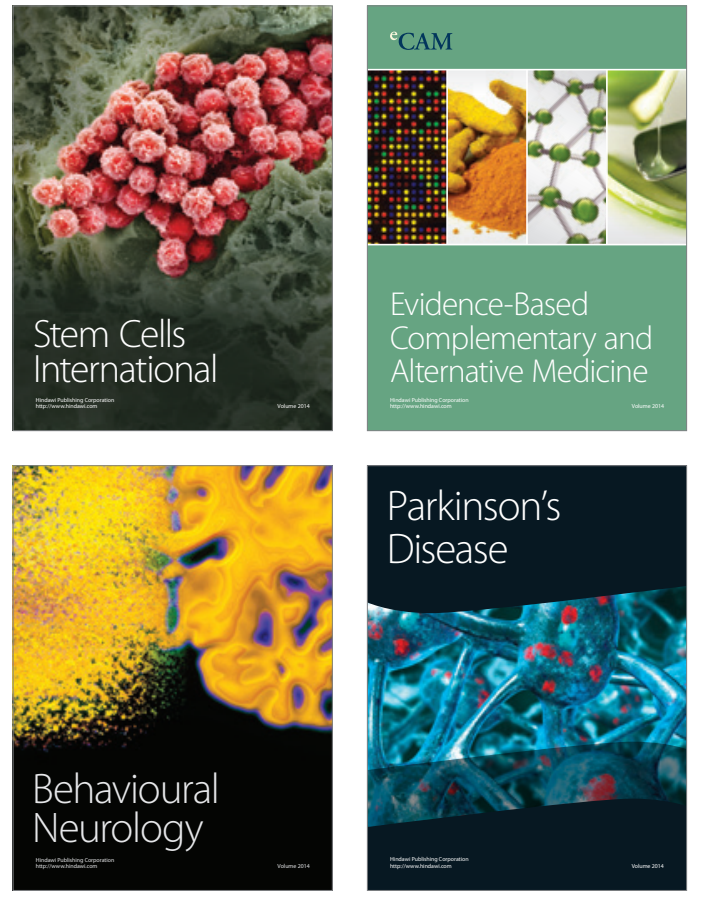
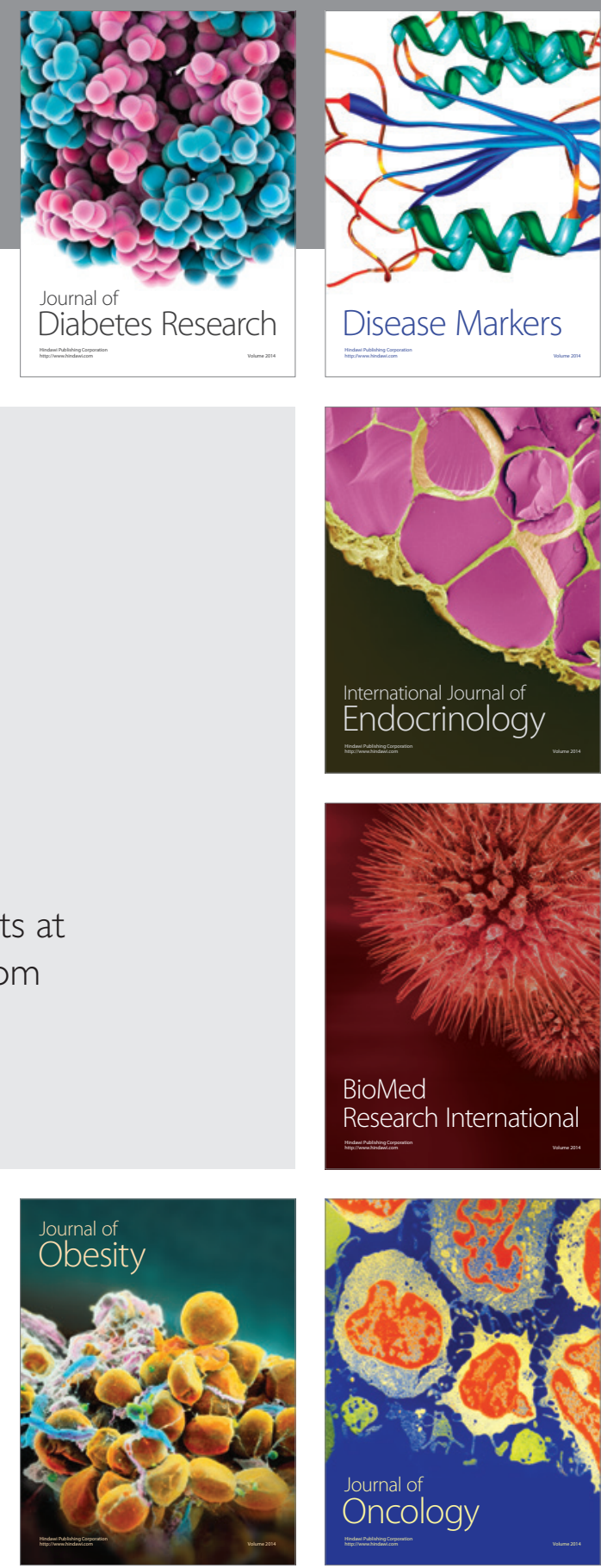

Disease Markers
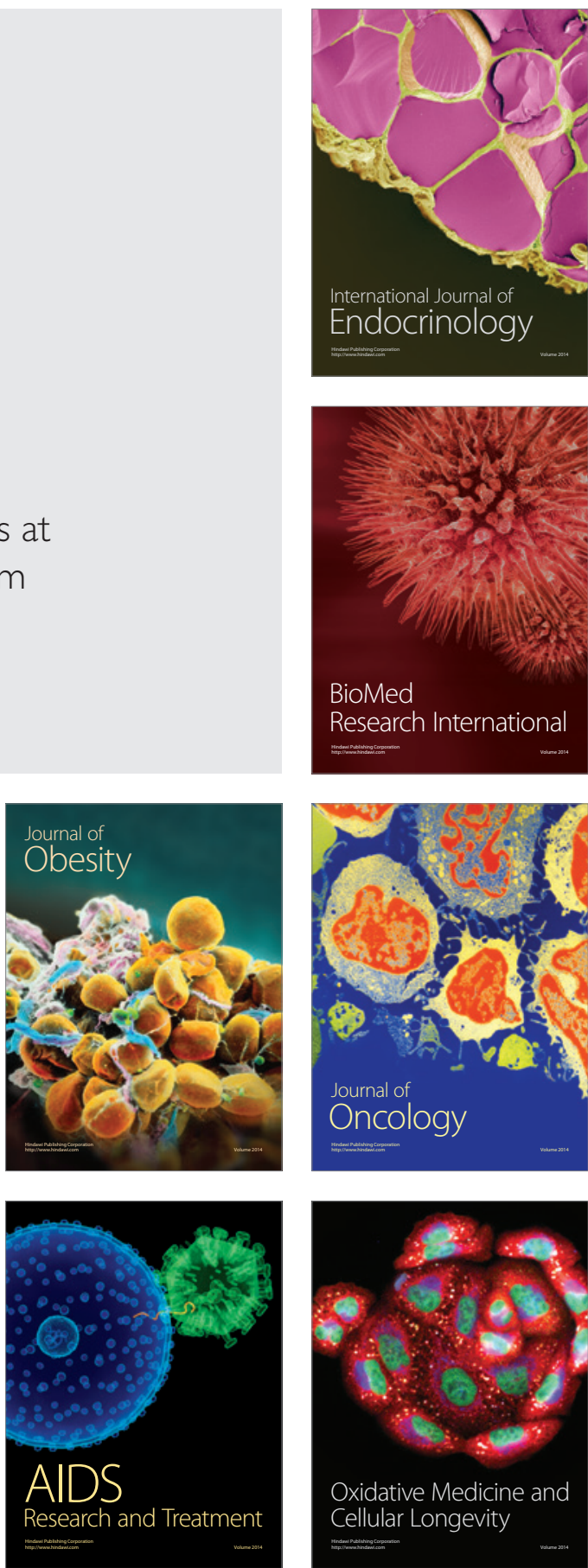